\title{
EDUCAÇÃO PARA VIDA SOCIAL DEMOCRÁTICA: AS ASSEMBLEIAS DE CLASSE NO ENSINO FUNDAMENTAL
}

\author{
Verônica Nogueira Vanni, Carmen Lúcia Dias \\ Universidade do Oeste Paulista - UNOESTE, Mestrado em Educação, Presidente Prudente, SP. E-mail: \\ veronica vanni@hotmail.com
}

\begin{abstract}
RESUMO
Este artigo tem como objetivo trazer à discussão as práticas morais na escola como instrumento importante na construção da autonomia das crianças do Ensino Fundamental I. Buscamos refletir sobre a educação democrática e sua fundamental importância na formação do cidadão autônomo, procurando evidenciar especificamente a contribuição de práticas morais deliberativas, as assembleias de classe. Para atingir tal objetivo, utilizamos como metodologia a pesquisa bibliográfica onde autores desta área propõem uma discussão acerca de questões pertinentes à educação democrática, bem como as práticas morais existentes nas escolas, ressaltando em seu eixo central as assembleias de classe. E com a contribuição desses autores podemos observar que diante da urgência social em construir um país onde haja além do respeito às diferenças, a participação dos indivíduos como cidadãos; as práticas morais nas escolas são de fundamental importância na ação educativa durante todo processo de escolarização, promovendo a autonomia moral e a convivência democrática.
\end{abstract}

Palavras-chave: Educação democrática, Assembleias de classe, Ensino Fundamental I.

\section{EDUCATION FOR DEMOCRATIC SOCIAL LIFE: THE CLASS MEETINGS IN THE ELEMENTARY SCHOOL}

\begin{abstract}
This article aims to bring the discussion the moral practices in the school how important tool in the construction of autonomy of children of the Elementary School I. We seek to reflect on the democratic education and its fundamental importance in the autonomous citizen formation, looking specifically highlight the contribution of deliberative moral practices, the class assemblies. For reaching this objective, we used as methodology the bibliographic research where authors of this area propose a discussion, just like the moral practices existing in the schools, highlighting in its central axis the class assemblies. And with the contribution of this authors we can observe in front of the social urgency in building a country where there be besides respect for differences, the participation of the individuals as citizens; the moral practices in the schools are of fundamental importance in the educational activity during all of educational process, promoting the moral autonomy and the democratic coexistence.
\end{abstract}

Keywords: Democracy education, Class meetings, Elementary School I. 


\section{INTRODUÇÃO}

Diante da realidade social que vivemos atualmente, um dos objetivos almejados pelas instituições escolares está em propiciar aos alunos o desenvolvimento da sua autonomia moral, para que estes se tornem cidadãos capazes de viver em sociedade e participar dela, agir de forma ativa e critica.

Fazer do ambiente escolar, um espaço que contribua e transforme práticas tradicionais em ações potencializadoras no intuito da formação do indivíduo pleno, intelectual e social, é ainda um grande desafio.

Um dos maiores desafios no sentido de preparar as novas gerações para extirpar a violência é, no campo da educação, ensinar a viver como pessoas. Nossa época reclama claramente uma urgência maior: ensinar e aprender a viver em sociedade. Essa tarefa exige uma revolução sociopsicológica e pedagógica que ainda está por se realizar. O horizonte educativo deve ser o de promover a autonomia do aluno, não só nos aspectos cognitivos, mas também em seu desenvolvimento moral e social. (MORENO, 2005. p. 94).

Desta forma, percebe-se a necessidade emergencial das escolas em planejar e promover ações educativas que garantam significativamente às crianças, aprendizagens não somente para exercitar atividades a fim de atingir os próprios objetivos, mas também para a aprendizagem da convivência em grupo, respeitando e compreendendo a diversidade social existente, ou seja, formando o indivíduo para a cidadania.

Complementa Araújo (2004)

[...] entendemos que essa formação deve visar ao desenvolvimento de competências para lidar com a diversidade e o conflito de ideias, com as influências da cultura e com os sentimentos e as emoções presentes nas relações do sujeito consigo mesmo e com o mundo à sua volta. Assim, tal modelo educativo entende que a escola pode atuar no sentido de promover a formação ética, política e psicológica de seus membros. (ARAÚJO, 2004, p.15).

Assim, reconhecer que a educação tem um papel fundamental em todo o processo da construção da autonomia moral para que atinja às finalidades aqui evidenciadas, consequentemente implica competir a ela também, além dos conteúdos curriculares, desenvolver práticas escolares sociais, políticas e morais, com vistas ao protagonismo do indivíduo no convívio de uma sociedade democrática, como aponta o relatório da Organização das Nações Unidas para a Educação, Ciência e Cultura (UNESCO),

A preparação para uma participação ativa na vida de cidadão tornou-se para a educação uma missão de caráter geral [...] fazer da escola um modelo de prática democrática que leve as crianças a compreender, a partir de 
problemas concretos, quais são seus direitos e deveres [...] (DELORS, 1996, p.61).

Desta forma, pensar no contexto social atual exposto acima requer a reflexão da finalidade educativa das escolas, valendo-se assim fortificar os objetivos da implementação de práticas morais na escola, as quais buscam resultar no trabalho com as crianças:

1 - Que adquiram um vivo reconhecimento da coletividade e que sintam parte do grupo no qual estão imersos. Que se sintam parte e que estejam dispostos a colaborar e a trabalhar pelo bom funcionamento da comunidade. 2 - Que aceitem e construam normas; isto é, que tenham adquirido um sentido autônomo de disciplina que os capacite para reconhecer a correção de certas normas escolares, para melhorá-las e para estabelecer outras normas que sejam capazes de otimizar a convivência.

3 - Que desenvolvam uma forte autonomia da vontade que os impeça de se esconderem no grupo e que, ao contrário, os impulsione a participar de acordo com seus critérios pessoais no bom andamento da sala de aula e da escola.

4-Que desenvolvam o conjunto de capacidades necessárias para dialogar de modo correto e para serem capazes de manter uma atitude reflexiva a respeito de si mesmos e da comunidade a qual pertencem.

5 - Que adquiram uma predisposição a se comportar de acordo com valores como o espírito de iniciativa, a responsabilidade, a cooperação, a solidariedade, a tolerância e a busca de acordos. (PUIG, 2002, p. 32- 33).

Neste contexto, este artigo tem por objetivo apresentar reflexões acerca do papel desempenhado pelas escolas democráticas, buscando evidenciar nestas instituições o trabalho fundamental desenvolvido através de práticas morais, em especial com as assembleias de classe, ressaltando a contribuição das mesmas nos espaços educativos para vivências significativas com vistas ao desenvolvimento moral e a formação plena do indivíduo.

\section{METODOLOGIA}

Esta pesquisa bibliográfica (SALVADOR, 1991), teve como aporte a revisão de literatura especializada, com autores que propõem uma discussão acerca de questões pertinentes à educação democrática, bem como as práticas morais existentes nas escolas, ressaltando em seu eixo central as assembleias de classe.

\section{DISCUSSÃO}

Singer (2010) destaca em seus estudos, uma das primeiras escolas com o modelo democrático: Summerhill. Fundada em 1921 na Alemanha pelo escocês Alexander Sutherland Neill 
e em funcionamento até os dias de hoje na Inglaterra, a instituição tinha como prerrogativa que o ensino devia ser desenvolvido com base na associação de atividades práticas concomitantes com os conteúdos, consequentemente, com maior envolvimento e a participação dos alunos, bem como intensa voz ativa nas decisões junto aos grupos. Posteriormente, muitas outras escolas, inspiradas pelo modelo de Summerhill, iniciaram o desenvolvimento de seu trabalho na mesma perspectiva, o que se pode considerar um grande crescimento ocorrido na ampliação das escolas democráticas ao redor do mundo.

Ainda de acordo com a autora, atualmente, se tem como referência para o nosso país, a escola da Ponte. Localizada em Portugal, é uma instituição educacional conhecida pelo desenvolvimento de um trabalho pedagógico e gestão democrática, sendo a gestão da escola conduzida por José Pacheco e seu grupo de educadores. A Escola da Ponte é o modelo hoje de escola democrática que vem sendo implantado em muitas escolas no Brasil, através da iniciativa de Rubem Alves, filósofo brasileiro que desde sua visita à instituição portuguesa, busca parcerias em instituições e secretarias de educação afim de expandir este modelo pedagógico (SINGER, 2010).

Muitas outras instituições escolares estão cada vez mais em busca de desenvolver uma metodologia de trabalho democrático no intuito formar cidadãos autônomos, o que significa um avanço para a transformação da educação e uma conquista grandiosa para as futuras gerações. Ressaltando que as escolas democráticas possuem características específicas em sua maneira de funcionar e de organizar-se, um aspecto fundamental de uma escola democrática está em sua gestão participativa, ou seja, toda a comunidade escolar participa dos processos decisórios.

Sendo assim, professores, alunos, coordenação, gestão e comunidade possuem voz ativa nos processos de construção e organização do currículo, projetos e atividades desenvolvidas na escola, deliberando coletivamente quais os caminhos que a escola deve percorrer para que melhor atinja seus objetivos educacionais.

Uma escola será uma comunidade democrática à medida que se abrir à participação de todos os envolvidos. Não há comunidade democrática quando a escola é regida por critérios organizacionais e morais de caráter autoritário. (PUIG, 2002, p. 32).

Ainda, segundo o autor, é necessário salientar

Uma escola democrática pretende que os alunos e alunas sejam protagonistas da própria educação e que o façam participando ou tomando parte direta em todos aqueles aspectos do processo formativo possíveis de deixar em suas mãos. (PUIG, 2002, p.27). 
A escola democrática, considera primordial no desenvolvimento de suas ações, a complexidade que se estabelecem as relações sociais, valorizando a inclusão, o respeito, as diferenças e proporcionando a participação de todos no processo educativo. Sendo assim, valoriza os conhecimentos prévios dos alunos, para que o exercício da democracia se desenvolva plenamente.

Além disso, os conhecimentos que os educandos trazem para a escola a partir de sua história de vida e de seus interesses pessoais devem estar no centro da contextualização dos conteúdos trabalhados em sala de aula. Considerar tal realidade na teia de conhecimentos a serem abordados na escola dará maior significado à aprendizagem dos alunos e alunas. (ARAÚJO, 2002, p.49).

Para tanto, a escola democrática, nesse sentido, desenvolve seu trabalho pedagógico com vistas à construção de uma consciência autônoma, que sendo a base para o exercício da cidadania e da convivência democrática, fundamenta-se no estímulo constante da reflexão, do diálogo, na expressão dos sentimentos e pontos de vista de todos, no exercício intencional de concretizar ações que refletem no encontro entre os objetivos escolares e os pessoais.

A formação de um indivíduo crítico, cidadão, autônomo e protagonista em seu meio social, proposto pelos Parâmetros Curriculares Nacionais (PCNs) tem se tornado cada vez mais o cerne das discussões nas propostas curriculares e cenários educacionais.

O objetivo de acordo com o documento

Concebe a educação escolar como prática que tem a possibilidade de criar condições para que todos os alunos desenvolvam suas capacidades e aprendam os conteúdos necessários para construir instrumentos de compreensão da realidade e de participação em relações sociais, políticas e culturais diversificadas e cada vez mais amplas, condições estas fundamentais para o exercício da cidadania na construção de uma sociedade democrática e não excludente (BRASIL, 2000, p.45).

Nesse sentido, muitos professores e escolas que efetivamente almejam os objetivos acima expostos, tem cada vez mais demonstrado preocupação em desenvolver um trabalho diferenciado, voltado à formação não só das questões que se referem ao desenvolvimento intelectual/cognitivo do aluno, mas também para a construção sóciomoral do mesmo, considerando a importância de inserir no ambiente educacional da classe, práticas que promovam uma melhoria da qualidade das relações interpessoais das crianças.

$\mathrm{Na}$ intenção de se construir escolas cada vez mais democráticas, onde o respeito mútuo e a tomada da consciência são aspectos essenciais para o estabelecimento de um ambiente cooperativo e harmonioso, práticas morais permanentes têm sido implantadas nos espaços 
escolares. Nas palavras de Puig "as práticas morais são maneiras estabelecidas de tratar culturalmente as situações sociais ou pessoais que acarretam dificuldades recorrentes" (2004, p.63), ou seja, de acordo com seus valores, o indivíduo busca de forma moral solucionar problemas e conflitos do seu cotidiano.

Ainda do autor

A educação moral é uma tarefa destinada a dar forma moral à própria identidade, mediante um trabalho de reflexão e ação a partir das circunstâncias que cada sujeito vai encontrando dia a dia. Trata-se, porém, de um processo de construção que ninguém realiza de modo isolado; conta sempre com a ajuda dos demais e de múltiplos elementos culturais valiosos, que contribuem ativamente para conformar a personalidade moral de cada sujeito. (PUIG, 1998, p.20).

Hoje, observa-se que a utilização das assembleias de classe vem frequentemente sendo adotadas pelas escolas. Inseridas na sala de aula, são valorosas oportunidades para a criança expor e refletir em conjunto com os demais os acontecimentos, expondo sua opinião e debatendo suas ideias livremente.

Os processos educacionais instituem práticas de deliberação que, por um lado, atuam na preparação da vida adulta; e por outro, na adoção de formas de convivência adaptadas às possibilidades de seus alunos, mas coerentes com as aspirações éticas da sociedade. (PUIG, 2004, p.118).

Estes momentos dão abertura também para a troca de experiências e busca de soluções coletivas para situações de conflito que aparecem no cotidiano escolar e até mesmo de prevenção das mesmas.

O modelo das assembleias é o da democracia participativa, que tenta trazer para o espaço coletivo a reflexão sobre os fatos cotidianos, incentivando os protagonismos das pessoas e a co-participação do grupo na busca de encaminhamentos para os temas abordados, respeitando e naturalizando as diferenças inerentes aos valores, às crenças e aos desejos de todos os membros que delas participam (ARAúJO, 2004, p.24).

É também por meio delas, que professores e alunos podem se conhecer mais, estreitando laços, alem de ser uma boa oportunidade de estabelecerem em conjunto, regras para melhor convívio do grupo.

Por certo, as assembleias são situações particulares que podem propiciar esse autoconhecimento: quando são convidados a falar sobre suas próprias interpretações das situações que ocorrem no grupo, os alunos falam de seus pensamentos e de seus sentimentos -falam de si. Sentem-se, portanto, 
valorizados, porque podem opinar, e, mais do que isso, sentem-se pertencentes a um grupo. (TOGNETTA, 2007, p.139).

O espaço das assembleias requer realmente ser valorizado, pois através dele pode-se alcançar uma aprendizagem democrática não só para alunos, mas também professores, gestores e funcionários. No entanto, é fundamental considerar não deve o educador limitar-se somente ao trabalho com as assembleias de classe, proporcionar outras práticas para atingir a autonomia moral da criança compreende desenvolver constantemente estratégias diversificadas que possibilitem que os alunos possam manifestar-se por meio de discussões coletivas buscarem soluções para os problemas que surgem.

Assembleias não são 'mágicas' ou panaceias que resolverão todos os problemas. É preciso cautela com falsas expectativas de que o objetivo destas seja a eliminação dos problemas. São, na verdade, mais uma possibilidade de resolução de conflitos e uma oportunidade para que crianças e adolescentes se sintam pertencentes ao grupo e responsáveis por este. É verdade, portanto, que, se são uma das possibilidades, haverá outras estratégias a serem realizadas decorrentes de um ambiente cooperativo. (TOGNETTA, 2007, p.100).

É importante salientar que as práticas com as assembleias de classe é um importante recurso que possibilita a participação das crianças nas questões que permeiam o universo escolar desde cedo.

No hábito de exercitar a reflexão e expressar seus pontos de vista respeitando o do outro desenvolve assim sua autonomia moral.

É preciso ensinar os alunos a pensar, e é impossível aprender a pensar sob um regime autoritário. Pensar é procurar por si mesmo, é criticar livremente e é demonstrar de maneira autônoma. O pensamento supõe, portanto, o livre jogo das funções intelectuais, e não o trabalho sob coerção e a repetição verbal. (PIAGET, 1998, p.154).

Concretizar ações nessa direção é possível, no entanto, é necessário às instituições escolares o rompimento de toda a estrutura pedagógica tradicional, buscando em ações condições que contribuam para uma formação onde as pessoas se relacionem harmoniosamente de acordo com regras e normas que regulam a vida em sociedade, ou seja, preparem o aluno para uma vida num processo de educação moral. 


\section{CONCLUSÃO}

Podemos concluir segundo o aporte dos autores, que diante da urgência social em construir um país onde haja além do respeito às diferenças, a participação dos indivíduos como cidadãos; as práticas morais nas escolas são de fundamental importância na ação educativa durante todo o processo de escolarização. Em especial, o trabalho com as assembleias de classe, necessita ser uma prática permanente, como cultura da escola pois, os espaços das assembleias possibilitam além da aproximação entre professores e alunos, a discussão de conflitos de forma democrática que resultam em decisões coletivas de decisões ou até mesmo ser este um espaço para o debate de ideias que busquem uma decisão em conjunto. Consequentemente, o desenvolvimento constante da prática propicia um ambiente onde o diálogo e a capacidade de autogovernar-se é manifesto nas crianças, ou seja, a construção da autonomia moral rege as relações interpessoais nas salas de aula. Desta forma, o trabalho com as assembleias de classe pode proporcionar às crianças a evolução moral, provocando um posicionamento positivo perante si mesmo e para a sociedade, aspectos fundamentais para a vida em uma sociedade democrática e a educação para a cidadania.

\section{REFERÊNCIAS}

ARAÚJO, U. F. Assembleia escolar: um caminho para a resolução de conflitos. São Paulo: Moderna, 2004.

ARAÚJO, U. F. A construção de escolas democráticas: histórias sobre complexidade, mudanças e resistências. São Paulo: Moderna, 2002.

BRASIL. Parâmetros Curriculares Nacionais: introdução aos parâmetros curriculares nacionais. Secretaria de Educação Fundamental. Rio de Janeiro: DP\&A, 2000.

DELORS, J. Educação um tesouro a descobrir- relatório para a UNESCO da Comissão Internacional sobre a Educação para o século XXI. São Paulo: Cortez, 1996.

MORENO, C. I. Educar em valores. 3.ed.São Paulo: Editora Paulinas, 2005.

PIAGET, J. Sobre a pedagogia. São Paulo: Casa do Psicólogo, 1998.

PUIG, J. M. A construção da personalidade moral. São Paulo: Ática, 1998.

PUIG, J. M. As assembleias de sala de aula ou como fazer coisas com palavras. In: ARGÜIS, R. Tutoria - com a palavra, o aluno. São Paulo: Artmed, 2002, p. 27-34.

PUIG, J. M; MARTIN, X.; ESCARDÍBUL, S.; NOVELLA, A. M. Democracia e participação escolar. São Paulo: Moderna, 2002.

PUIG, J. M. Práticas morais: uma abordagem sociocultural de educação moral. São Paulo: Moderna, 2004.

SALVADOR, A.D. Métodos e técnicas de pesquisa bibliográfica. Porto Alegre: Sulina Editora, 1991.

SINGER, H. República de crianças: sobre experiências escolares de resistência. Campinas, SP: Mercado de Letras, 2010. 
TOGNETTA, L. R. P.; VINHA, T. P. Quando a escola é democrática: um olhar sobre a prática das regras e assembleias na escola. 2- Reimpressão. Campinas, SP: Mercado das Letras, 2008. 